\title{
Preliminary Analysis of Business Learners' Needs
}

\author{
Awicha Benabdallah, Assistant Professor \\ Preparatory School of Economics and Commercial Sciences, Tlemcen, Algeria \\ Email: benabdallah333@yahoo.co.uk
}

\section{Doi:10.5901/mjss.2015.v6n6p519}

\begin{abstract}
With the increasing aim of matching the objectives of the language course to learners' requirements, the process of Needs Analysis and Identification (NAI) is believed to be central to the entire discipline of ESP. However, reaching a decision upon the manner and the time to administer and analyse it, is seen as a challenging assignment for syllabus designers including ESP practitioners. This latter is subject to a strategic organisation and conceptual knowledge of the theories of learning, approaches to ESP course design and types of the syllabus. This present investigation is exploratory, descriptive and explanatory in its nature undertaken through a case study of the second-year students in the preparatory school of Economics and Commercial Sciences of Tlemcen, Algeria. It was set out to hopefully examine the ESP teaching situation. Therefore, a Needs Analysis and Identification (NAI) was constructed and administered for the aim of fulfilling their requirements.
\end{abstract}

Keywords: ESP, business English, Needs analysis and identifications, course design.

\section{Introduction}

Today in 2015, our world is enormously influenced by some crucial aspects namely the ongoing globalisation process, the existence of the global marketplace, development in the realm of science and technology, the advent of information and communication technologies. In the light of these events, speakers all over the globe, regardless of their mother tongue and their scope of interests, are governed by the need to learn a worldwide language as a prerequisite to undertake some academic and professional assignments such as reading scientific articles and writing reports.

The changes experienced in the field of general language teaching remain unprecedented to fit the various demand and the challenges of our multi-dimensional facet of this one-world-order. Therefore, a new tendency in education has been progressively oriented towards implementing and devising suitable specialised language courses (or what is known as that of English for specific purposes) to cope, mainly, with the needs of the language speakers to perform effectively in their specific target discourse setting.

\section{Theoretical and Conceptual Framework}

For the sake of meeting the challenges confronted by different language users, ESP has witnessed, throughout its history, significant stages of development. Moreover, several speculations have been made in an attempt to fit different learning situations, starting from the traditional category of whether the language is needed in the academic context (EAP) or rather used to achieve specific tasks in the workplace environments (EOP) (Strevens, 1977; Robinson, 1980, 1991; Bolitho \& Kennedy, 1984). Hutchison \& Waters (1987), in contrast, classify ESP into three main headings according to their tree of ELT namely English for Science and Technology (EST); English for Business and Economics (EBE); English for Social Sciences (ESS). Each one in itself is split up into EAP and EOP.

The growing demand for English in the economic framework on wide-ranging levels as being "...the primary language for doing international business" Estaban \& Pérez Cañado, (2004:137) leads this specialised course to become amongst the most well-received sort of ESP instruction worldwide. Several acronyms and classifications have been adopted by academic scholars in an effort to describe it. According to Hutchinson \& Waters (1987), it is named EBE and is broken down into two sub-categories on the basis of whether the language is required by economists or secretaries.

Dudley-Evans \& John (1998), on the other hand, label it English for Business Purposes (EBP) and classify it as belonging to the sub-group of English for Professional Purposes. They also make a further distinction between the general and specific contexts of language use. Therefore, in this plethora of discussions, one may say that the underlying aim of this kind of language course, in general, is to assist learners to become competent language speakers in their target educational setting and prepare them, at the same time, for their prospective professions as supported by 
Hutchinson \& Waters (1987:16) "it is also likely that in many cases the language learnt for immediate use in a study environment will be used later when the student takes up, or returns to a job."

From this layer of analysis, it should be noted that English is not only requested by business workers whose rationale is to attain daily achievements in their business and commercial spheres. The language is also, required to cope with the demand of our large-scale academic contexts such as reading authentic articles and making oral presentations, writing abstracts and reports. This idea has been mentioned by Gore (2007: I):

In today's business world, anyone working in marketing or advertising needs English in order to do their job. Whether you are talking to clients, discussing new advertising campaign for your company, establishing a new marketing plan, or writing press release - you will be using English more and more.

Like any other form of ESP Teaching, the process of Needs Analysis and Identification (NAI) has received a considerable attention and viewed as a mass requirement for the design of EBE course as well to cater for the learners' specific language skills, knowledge and abilities. This has been argued by Dudley-Evans and John (1998: 57) "needs analysis may be even more fundamental in Business English ....as learners' needs can be much more varied and the spectrum of language and skills less predictable."

Additionally, the burgeoning literature on EBE needs Assessment insists on the identification of how language is used by its discourse community, what specific business genres are needed e.g. business letters, emails, memos, reports and for what communicative events e.g. agreeing, disagreeing, telephoning, accepting and rejecting (Swales, 1990; Charles, 1996).

Moreover, several approaches to needs analysis have been reported namely Target situation and learning situation (Hutchinson \& Waters, 1987); Objective and subjective needs (Brindley, 1989); Percieved needs and felt needs (Berwick, 1989). Pedagogic needs analysis' (West, 1998). The following diagram is an attempt to sum up each approach:

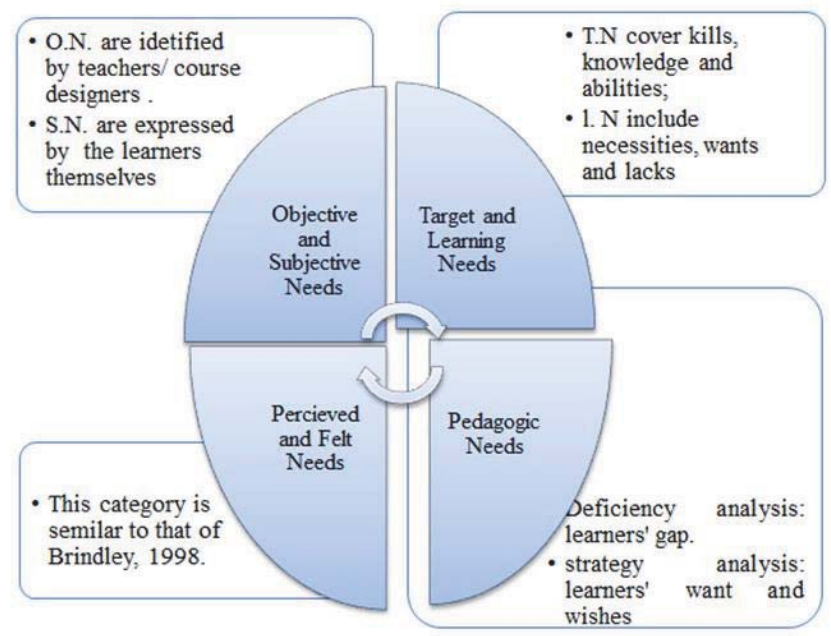

Diagram 1. Approaches to Needs Analysis

To put in a nutshell, this process is widely acknowledged in language teaching in general and believed to be a cornerstone in ESP situation in particular. Analysing the learners' needs requires providing suitable answers to some underlying questions as who is concerned with the course, what do they need to learn, and where the language is taught (Hutchinson \&Waters, 1987).

\section{Environmental Analysis}

Due to the importance of ELT worldwide, Algeria, like many other countries, has adopted English as a foreign language since its independence. Therefore, general language courses have been implemented in both governmental and nongovernmental establishments. Several types of ESP instruction have been, also, offered in its tertiary education and some professional organisations in order to equip learners with specific language skills, jargon and specialised 
knowledge depending on their area of studies and urge them to achieve what is labelled 'communication among specialists'.

As it has been mentioned before, the process of Needs Analysis and Identification is seen as an umbrella activity that goes beyond an analysis of the present situation. Another significant examination is of great importance to gather data of different factors that may influence the ESP practice and will be drawn on to improve the ESP teaching situation.

This present section is, thus, used as a modest attempt to provide a brief rundown of the ESP teaching situation at the preparatory school of Economics and Commercial Sciences, Tlemcen, Algeria. This academic institution affords a mandatory Business English course for both first and second-year students allocated for three hours per week. However, science is prized over languages in this educational setting, which results in the fact of scheduling ESP instruction at the afternoon.

Most of the teachers in charge of ESP education at this school are full-time instructors. They are post-graduated from Tlemcen University, Algeria, they received theoretical preparation in only TEFL and sociolinguistics. Moreover, none of them receives intensive or extensive training in the field of ESP in general or Business English in particular. Moreover, what is debatable at this level is that there is a total absence of instructional materials provided by the Algerian Ministry of Education and Scientific Research to teach business students in the preparatory school of Economics, Tlemcen, Algeria. ESP practitioners are, therefore, relying on themselves to analyse their learners' needs, design adequate courses and evaluate the language progress.

\section{Aims and Objectives of the Study}

The present research serves as a preliminary study. It is almost an attempt to analyse the business learners' needs. Therefore, the fundamental guiding objectives are as follows:

- To describe the ESP teaching situation at the preparatory school;

- To identify the ESP learners' difficulties;

- $\quad$ To know what language skills are most needed by the learners;

- $\quad$ to bridge the gap between the learners' lacks and wants by designing appropriate courses.

\section{Research Questions and Hypotheses}

The main enquiries that were addressed at the heart of this present investigation to design ESP courses in accordance with the learners' requirements are as follows:

1. Is the ESP course offered at this school appropriate to the learners' needs?

2. Why do our Algerian ESP learners in the preparatory school of Economics and Commercial Sciences need English for?

3. What are the learners' language difficulties?

4. What types of ESP course might fit these ESP learners' requirements?

The following hypotheses were reformulated to provide answers to the above-mentioned research questions,

1. Though ESP teaching is implemented at the school, it may not be systematically based on the students' needs.

2. The Algerian ESP learners in the Preparatory School of Tlemcen may need English to achieve academic success which is related to the fact of passing language exams and the contest at their second-year.

3. The ESP learners may have difficulties in speaking skills and specialised terminology.

4. A skill-based approach to ESP course design may be most appropriate the ESP learners' needs.

\section{Research Design, Methods and Procedures}

The success or failure of any educational investigation is determined by a number of essential factors notably the type of the research approaches, the size and suitability of the sampling and the elicitation techniques. They should be selected in a systematic way to meet the objectives, the research questions and hypotheses of the present study.

\subsection{The Sample Population}

The process of sampling plays a critical function in an educational research for its ability to save a great deal of efforts and time required for the accomplishment of the work, to reduce biased, unreliability of the findings and to obtain 
sometimes the generalisability of the results (Sapsford \&Jupp 2006).

As far the sample population is concerned, this present study was based on a non-probability sampling. The investigator made use of a convenience technique for the selection of one group of twenty (20) second-year students coming from technical and scientific streams. Criteria for selection of these subjects were only a matter of the easy accessibility to the students, and the fact that at this level, they are old and supposed to be aware of their needs. Additionally, the researcher opted for a purposeful procedure for the selection of five (5) available ESP teachers at the preparatory school of Economics and Commercial Sciences. However, it should be mentioned that this sampling procedure does not aim to generalize the results to the wider population but rather to provide a clear description of the study under investigation.

\subsection{Research Methodology}

To gather in- depth data about the ESP learners' needs, difficulties and ESP teaching situation, the researcher opted for a case study at the Preparatory School of Economics and Commercial Sciences, Tlemcen. This approach is widely acknowledged in educational setting for its ability to be conducted in its real framework. Besides, it permits to provide an insightful examination and reach a thorough understanding about the subjects under investigation. (Dörnyei, 2007), similarly, Cohen et al., (2000:181) define it as providing "... a unique example of real people in real situations, enabling readers to understand ideas more clearly than simply by presenting them with abstract theory or principles"

Taking into account that the use of one data gathering research tool tends to provide limited information as far as analysing the learners' needs which constitutes wants, lacks and necessities, the methodological approach undertaken in this study was a mixed methodology based on a combination of both qualitative and quantitative research instruments to have multiple of data sources which allows for cross-checking the results, constructing the validity of the research questions and enabling the researcher to reduce bias. Therefore, data were collected through the administration of learners' questionnaire, teachers' semi-structured interview and the use of an overt- participant observation.

In order to reduce the problems that might occur at the administration and interpretation of the questionnaire and interview items, it is worth noting that the research tools were first piloted to a small number of informants. Therefore, some questions were adjusted, others were completely ignored because of their irrelevance of the current purpose of the research.

\subsection{Findings and Interpretation}

Concerning the findings obtained from the three data gathering instruments, the main results revealed that the majority of the students expressed their dissatisfaction about the ESP course as it did not meet their primary needs. This may be due the fact that teachers did not well analyse and interpret their learners' needs before the administration of the course. Another key reason is that they did not receive any intensive or extensive training sessions to teach business English. Teachers themselves expressed their lack of specialized terminology, practical way of NAl, and course design.

There was a general agreement among informants on the importance of English as being an international language. However, with reference to their language proficiency, $75 \%$ of them assessed their language ability as being intermediate and only $20 \%$ of the informants stated that they had a beginner level.

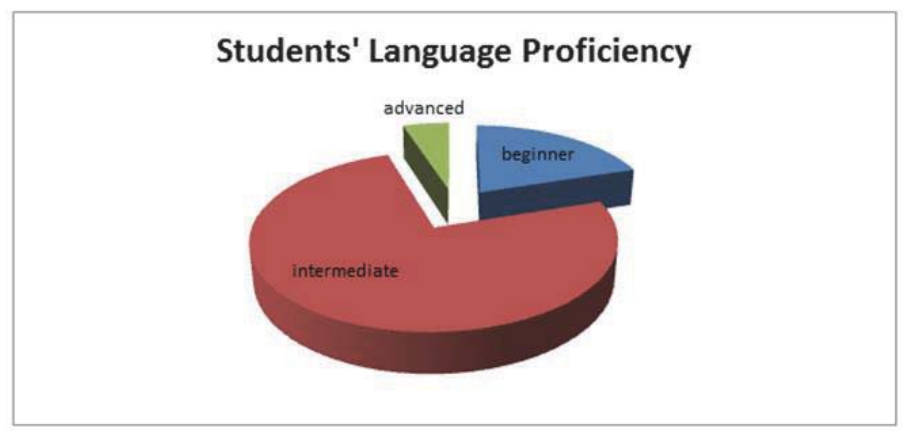

Diagram 2. Students' Language Proficiency. 
Regarding the purposes for learning English, learners expressed different reasons summarized in the following table:

Table 1. Purposes for Leaning English.

\begin{tabular}{|l|c|c|}
\hline Purposes & A F & R F \\
\hline Understanding lectures in their field of study in English. & 00 & $00 \%$ \\
\hline Taking part in oral communication & 18 & $90 \%$ \\
\hline Reading textbooks in their field of study in English & 10 & $50 \%$ \\
\hline Writing answers to examination questions & 20 & $100 \%$ \\
\hline
\end{tabular}

As has been shown in the above table, there was a general consensus among ESP learners that a high percentage was for being able to provide answers to examinations, that is to say, their primary aim was to fulfil their academic needs which includes reading comprehension and writing short essays as they are required to sit for a final exam at their second-year which allows them to have access to a number of higher schools.

Speaking about the students' needed skills, teachers agreed on the fact the stress should be put on the reading skills as being part of their examination. Moreover, they urged to use authentic materials in ESP teaching from different data sources such as audio-recording, scientific articles, textbooks for its significant aim of providing learners with the contextual framework of language as used by native speakers. This may enable learners to learn real world language in addition to the most up-to-date content. Learners, on the other hand, reported that speaking is the most needed skill believing that in their field of study, a language is used to perform different of functions. The following diagram sums up the skills according to their importance:

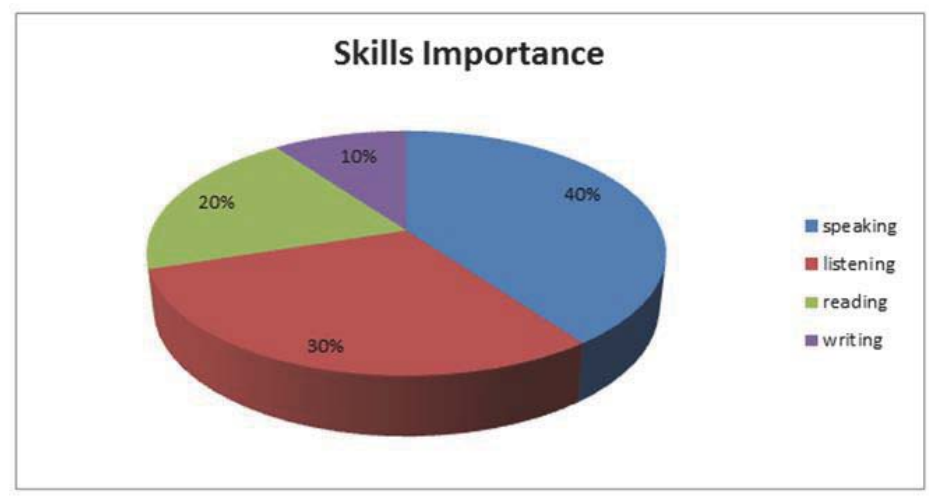

Diagram 3. Students' Perception about the Importance of the Skills.

As far as the learners' difficulties, the following set of problems was identified:

- Low level of language ability;

- Passive learning as teachers' talk constitutes a high portion of time;

- Lack of motivation and interests on the type of ESP courses;

- Lack of the use of language strategies;

- Focusing on the text as a linguistic objects rather than a vehicle of information.

With respect to the most suitable approach to ESP course design, a suggestion is based on making use of the skill-based approach. However, being aware of the interactive nature of the four skills namely reading, writing, speaking and listening, it should be pointed out that the process of teaching involves more than interpreting and evaluating information from spoken or written language. This stresses the need to focus on the students' learning (sub-skills and strategies) rather than a given skill as a separate process.

Due to the learner' low language ability, a consolidation and reinforcement of the ESP students' linguistic knowledge while teaching any skill are believed to be of great importance. This activity refers to what Spada (1997: 72) defines as: "Any pedagogical effort which is used to draw the learners' attention to language either implicitly or explicitly"

Pedagogical materials should be selected according to the learners' interest and demand. Teaching activity should 
focus on some strands which are meaning-focused input, language- focused learning, meaning-focused output. In this respect, attention to meaning is seen as a fundamental concern in teaching any language skill. The primary objective in learning business English is to first prepare learners to know or understand what the discourse is about. As a result, this should be accomplished through the use of interesting texts, enjoyable activities which include comprehension questions that help readers to interact with the texts and make meaningful production.

\section{Conclusion}

The purpose of this present case study is to identify and analyse the business learners' needs at the preparatory School of Economics and Commercial Sciences. Different research instruments were used in the data collection phase. Results showed that the learners have different purposes in learning the language. Practical recommendations were made to bridge the gap between the academic and professional needs through the implementation of a skill-based approach to ESP course. Another implication is that the language learning difficulty is not only tied to their lack of the required skills and strategies but also, and more precisely, their linguistic knowledge plays a centre role. Teaching, thus, requires not only focussing on a given language skill but also concentrating on teaching some grammatical points that cause the students' misunderstanding of meaning.

A key strength of this research work is that the process of Needs Analysis and Identification (NAI) provides a framework for suggesting a suitable ESP course. Moreover, the use of three data collection tools is also acknowledged in an educational research for cross-checking the results. It is to be mentioned that it is used as a pilot study for a PhD research. Further study could assess the effects of skill-based approach on the students' reading ability and language proficiency.

However, this study is subject to some limitations such as the small sampling size which may not provide the generalisability of the results. Additionally, the data gathered about the language difficulties from the research instruments may not be sufficient; they should be supported by administration of a proficiency test which aims at diagnosing the learners' state of knowledge, their language ability and learning difficulties.

\section{References}

Berwick, R. (1989). Needs Assessment in Language Programming: from Theory to Practice. In R. K. Johnson (Ed.) The second Language Curriculum. Cambridge: Cambridge University Press.

Brindley, G. (1989). The role of Needs analysis in Adult ESL Programme Design. In R. k. Johnson (Ed.). The Second language Curriculum. Cambridge: Cambridge University Press.

Charles, M. (1996). Business Negotiations: Interdependence between Discourse and the Business Relationship. English for Specific Purposes, 15:19-36

Dörnyei, Z. (2007). Research Methods in Applied Linguistics. Oxford University Press.

Esteban, A. \& Pérez Cañado, M.L. (2004). Making the case method work in teaching Business English: a case study. English for Specific Purposes, 23(2), 137-161.

Gore, S (2007). English for Marketing and advertising. Oxford (GBR); New York; Paris: OUP. Oxford University Press.

Hutchinson, T \& Waters, A. (1987). English for Specific Purposes. Cambridge University Press.

Kennedy, C \& Bolitho, R (1984). English for Specific Purposes. Macmillan Press Ltd; London.

Robinson, P. (1980). English for Specific Purposes. The Present Position. Pergamon Press.

Robinson, P. (1991). ESP Today: A Practitioner's Guide. Prentice Hall International

Spada, N. (1997). Form-Focused Instruction and Second Language Acquisition: A Review of Classroom and Laboratory Research. Language Teaching, 29, 73-87.

Sapsford, R, \& Jupp, V. (2006). Data Collection and Analysis. Sage Publications.

Strevens, P. (1977). Special Purpose Language Learning. A Perspective Survey article language Teaching and Applied Linguistics Abstracts, 10, 145-16

Swales, j. (1990). Genre analysis: English in Academic and Research Settings. Cambridge: Cambridge University Press.

West, R. (1998). ESP- State of the art. Available at: www.man.ac.uk/CELSE/esp/west.htm 